\title{
DETOURS AND BACKBOADS
}

\section{TWENTY-FOUR HOURS OF BARBECUE}

AS WE ITSTENFD TO GENTRAL TFXAS BARBECUE FOLKS DESCRIBE

their days, we realized that barbecue-related events happen around the clock. Fere is one look at a full day in Central Texas, twenty-four hours of barbecue.

1:00 A.M. The McMurtrys can log on to their home computer and check the temperature of sausages in their Smokey Denmark Sausage factory through a wireless probe communicating with a computer server in Dallas.

2¥00 A.ML. Ronnie Vinikoff begins driving from Rockdale to Austin with crates of wood on the back of his truck. He aims to finish the run by six so as to miss Austin's traffic.

3:00 A.M. Joe Capello heads into City Market in Luling. By half past the hour, he has put the briskets that have been seasoning overnight onto the pit.

$4=00$ A.M. Luke Zimmermann and Pat Mares are likely in bed at this hour, but fifteen years ago, they were just closing Ruby's Barbecue down after a busy night serving patrons from Antone's and Austin's other hopping music venues.

5:00 A.M. Briskets that started marinating two days ago at the Taylor Cafe get put onto the pit by Vencil Mares's helper. They will be ready by eleven, when the restaurant starts lunch service.

6:00 A.M. Don Wiley and his wife hit the road with a newly handcrafted smoker in tow, heading to Colorado to deliver a taste of home to a displaced Texan.

7:00 A.M. Contractors roll into condominiums being built across from East Austin's Ben's Long Branch Barbecue. Loud nail guns and concrete trucks overwhelm morning restaurant sounds.

8:00 A.ML. Potatoes start getting peeled, beans picked, and white bread wrapped in baggies at the New Zion Missionary Baptist Church in Huntsville. Horace Archie runs any other errands the Church of the Holy Smoke needs.

9:00 A.M. Another batch of sausage goes in the grinder at Burton Sausage. Dry sausage gets smoked four times before traveling to storefront cases.

10:00 A.M. At Southside in Elgin, cabbage is chopped, jalapeños are readied for pickling, and the sausage production is checked. As has occurred for more than 125 years, The Market gets ready for another day of business.

11:00 A.M. Bobby Mueller puts out the flag at Louie Mueller Barbecue in Taylor. When the flag is out, the restaurant is open.

NOON As many as 560 people can settle in, without forks or sauce, to a weekend lunch at Kreuz Market in Lockhart. No one misses either.

1:00 P.M. Richard Lopez considers leaving the Gonzales Food Market to take lunch or go fishing, but he stays put because he doesn't want to miss anything. Taking out a knife, he taste-tests the day's sausage.

2:00 P.M. Joe Sullivan closes down House Park Bar-B-Que after another busy lunch-no reason to work any more than the seventeen and a half hours a week he already does.

3:00 P.M. Terry Wootan drives the Cooper's Old Time Pit Bar-B-Que van to the Llano airport. He picks up passengers who have flown from Houston and Dallas to refuel and eat barbecue.

4,00 P.M. Representatives from Meyer's Sausage Company prepare demonstration tables in local grocery stores. While they used to give out the garlic at such events, now they use the plain.

5:00 P.M. Catering trucks depart from Pok-eJo's facility in Round Rock. Someone's Aunt Edna and other partygoers soon will get a taste of Texas to reminisce about when they're home.

6:00 P.M. The new air conditioning is on, stations are ready, and the waitstaff at the Salt Lick in Driftwood starts its busy night of serving customers, some of whom have waited two hours.

7:00 P.M. The audience gathers at Artz Rib House in Austin. Tuesday means old-time Texas fiddlers; later in the week, anything goes.

8:00 P.M. A refrigerated truck with directions in the cab lets hunters heading home drop off wild 


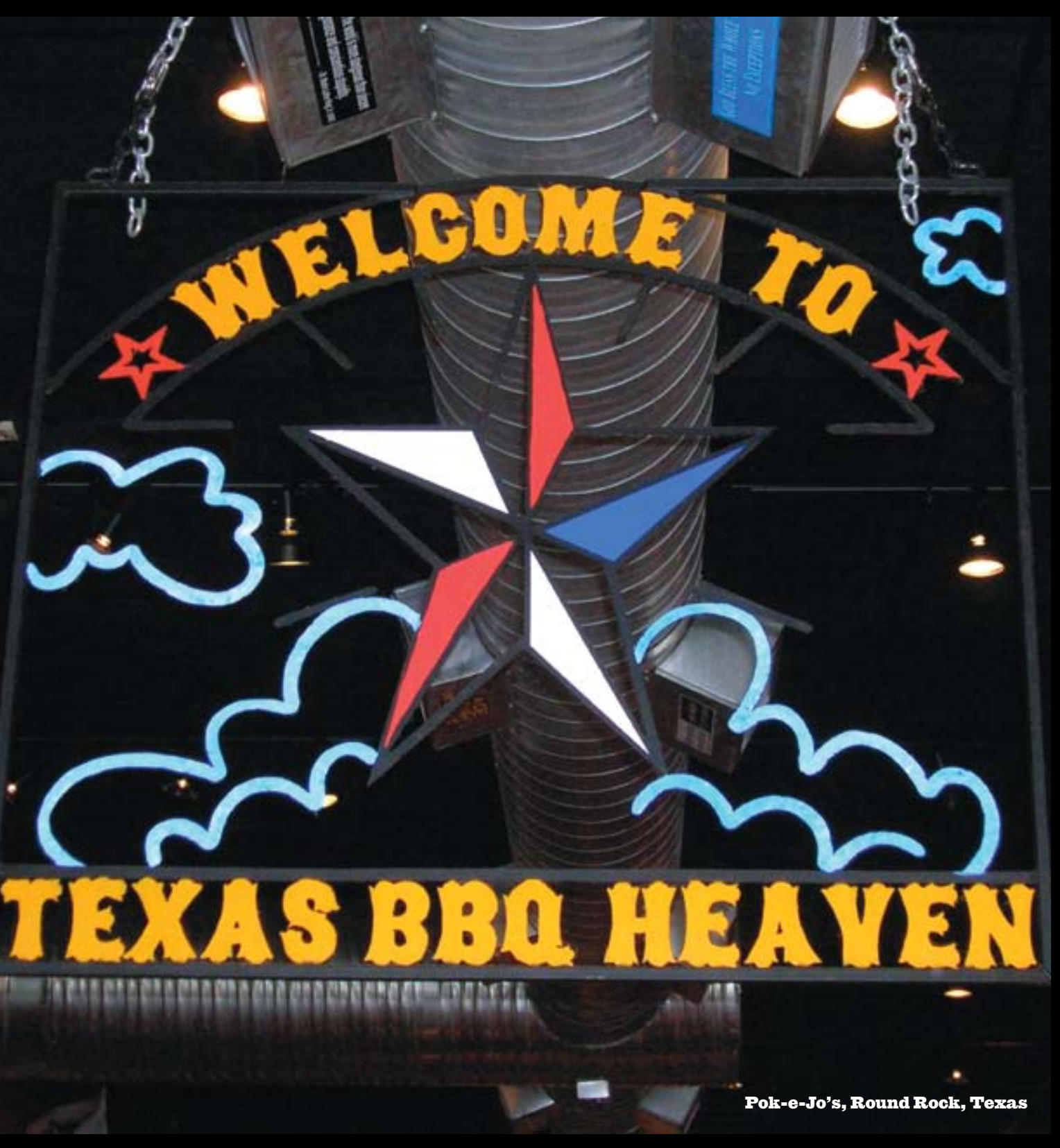

game after hours around back at Dziuk's Meat Market in Castroville.

9:00 P.M. Billy Inman returns to Inman's Ranch House in Marble Falls to stoke the fire for the night. His briskets cook slowly all night long. 10:00 P.M. You can't feed half a cow, but you can make sure all the whole cows are settled down for the night, so workers perform one last check at the Gonzales feedlot of Graham Enterprises.
11:00 P.M. Lines form at the Barbecuties kiosk on Sixth Street in Austin. Bustling bars mean hungry people wanting brisket to fuel a long night of partying.

MHDNIGIT Sam's Barbecue in East Austin is at its busiest now as bars start emptying and people make a last detour for ribs. The party and the barbecue roll on for twenty-four more hours, seven days a week, in our nonstop barbecue culture. 